\title{
On the Path of Poisonous Animals: A High School Game for Approaching Venomous Animals, Biotechnology Potential and Biodiversity
}

\author{
Juliana M. Diniz'1 , Ana Oliveira Carvalho², Rosane M. S. Meirelles ${ }^{1^{*}}$, Helena C. Castro ${ }^{1,2,3,4^{*}}$ \\ ${ }^{1}$ Programa de Pós-graduação em Ensino e Biociências e Saúde, IOC, Fundação Oswaldo Cruz, Rio de Janeiro, RJ, Brazil \\ ${ }^{2}$ Programa de Pós-graduação em Ciências e Biotecnologia, IB, Universidade Federal Fluminense, Niterói RJ, Brazil \\ ${ }^{3}$ Curso de Mestrado Profissional em Diversidade e Inclusão, IB, Universidade Federal Fluminense, Niterói RJ, Brazil \\ ${ }^{4}$ Programa de Pós-graduação em Ciências, Tecnologia e Inclusão, IB, Universidade Federal Fluminense, Niterói RJ, Brazil \\ Email: ^hcastrorangel@yahoo.com.br, ‘rosanemeirelles@gmail.com
}

How to cite this paper: Diniz, J. M., Carvalho, A. O., Meirelles, R. M. S., \& Castro, H. C. (2021). On the Path of Poisonous Animals. A High School Game for Approaching Venomous Animals, Biotechnology Potential and Biodiversity. Creative Education, 12, 1160-1168.

https://doi.org/10.4236/ce.2021.125086

Received: February 12, 2021

Accepted: May 28, 2021

Published: May 31, 2021

Copyright (C) 2021 by author(s) and Scientific Research Publishing Inc. This work is licensed under the Creative Commons Attribution International License (CC BY 4.0).

http://creativecommons.org/licenses/by/4.0/ (c) (i) Open Access

\begin{abstract}
Some animals present venom, which is a mixture of several molecules used as a biological weapon against natural enemies or preys. Several of these animals are part of the huge Brazilian biodiversity and these venoms have a huge biotechnological potential as feasible natural drugs for treatment of important diseases such as thrombosis. Since educational games are described as auxiliary tools for teaching complex themes, in this work we constructed a school game about venomous animals including protective instructions when in contact with some of them. The purpose of our game named "On the path of venomous animals" was to teach about this theme. It was constructed based on previous concepts of Brazilian high school students and approaches important topics (e.g. how to act when bitten by snakes) presented in a board format with cards containing the questions to be answered about different situations (luck or mischance). The game requests teacher's participation, and involves simulations of everyday life situations as well as the risk of encountering a poisonous animal. We tested the game with high school students aged from 16 to 18 years and despite most of them did not know much about these animals they were very interested on them. The use of this playful game as an educational instrument may allow learning about biodiversity whereas enhanced their perception of venom biotechnology potentiality.
\end{abstract}

\section{Keywords}

Game, Venomous Animals, High School, Biodiversity, Biotechnology

Potential 


\section{Introduction}

In the educational process, the use of games is known as a facilitator of the teaching and learning process as well as for children development as it allows reasoning and amusement whereas integrates them in the scholar social group (Malone \& Lepper, 1987; Jacobs \& Baum, 1987; Pierozan \& Brancher, 2004).

Board Games can be used to approach complex topics in biology (Cardoso et al., 2008). On that purpose, venomous animals are a complex theme to be presented at Brazilian schools as accidents involving these animals occur in a significant number every year in Brazil and also in the world (Brasil, 2020a). The knowledge about these animals allows adopting a preventive behavior and/or proper treatment against the envenomation.

The concepts and attitudes about venomous and poisonous animals are normally confused due to its complexity and few informative materials (Azeredo et al., 2020). Venomous animals are those with a gland that produces poison and an apparatus (e.g. teeth, stings, thorns, capsules, bristles) capable of inoculating it on a prey (Brazil, 2020b); whereas the poisonous animals produce poison, but don't have these anatomical apparatus, causing the poisoning through contact, compression or ingestion (Amaral, 2001).

The knowledge about these groups of animals is important as we need to: a) know how defend ourselves or how to proceed in case of the attack of these animals (Dossenbach, 1999) and b) know how to explore their potential exemplified by compounds such as captopril, a drug for hypertension created based on a snake venom molecule (Bryan, 2009). Thus, it is important not only to stand out their harmfulness feature but also their utility and biotechnological potential (e.g. bees and honey).

Thus, in order to address these issues, herein we described the development of a game about venomous and poisonous animals. Our purpose was to teach not only about their differences but also to exemplify about their biotechnological aspects, also promoting interaction and inspiring curiosity regarding them.

\section{Methods}

\subsection{Planning the Game}

The creation of the game was based in two aspects: 1) the previous conceptions of high school students of the third year of a regular school about the subject venomous and poisonous animals, and 2) the content about this topic on books and specialized sites in the subject.

We analyzed the previous concepts of students of two schools in Rio de Janeiro State including: 1) the difference between venomous and poisonous animals, 2) identification of poisonous animals, 3) aversion and fear of venomous animals, 4) importance of the knowledge and identification of these animals, 5) main venomous and poisonous animals of Brazil, 6) occurrence of accidents with venomous animals with the students and their families, and 7) attitudes that they acquire when find out more about venomous animal. 
The choice of the third year for the survey of the conceptions was based on the fact of the students have already been in contact with zoology themes, as these are topics suggested by the Brazilian National Curricular Parameters to students of high school second year.

The students that participated $(n=22)$ belongs to private and public high schools in Rio de Janeiro State. We used a questionnaire elaborated and previously tested by specialists in the education area (not shown). The project was approved by the Committee of Ethics of the Fundação Oswaldo Cruz (Fiocruz) by the number $377 / 03$.

For choosing the topics about the theme, we had selected didactic books of sciences $(\mathrm{n}=4)$ and biology $(\mathrm{n}=4)$ indicated by teachers of public $(\mathrm{n}=15)$ and particular $(n=10)$ schools as being amongst the most used and adopted books by schools in Rio De Janeiro State. In order to evaluate the venomous and poisonous animal subject in the books, we previously established searching topics including: correct definition of venomous and poisonous animals, examples of these animals, anatomical structures, poison role and treatment.

\subsection{Creating the Game}

The game was named "On the path of venomous animals" and created as a board, that demands teams' formation. The board in form of a tray $(120 \mathrm{~cm} \times 80$ $\mathrm{cm}$ ) is a track subdivided in 30 "houses" or spaces. Pieces that represent the name of the teams (A, B, C and D) walk in the spaces divided by 6 different environments: House, City, Forest, Field, Sea and Health Station (Figure 1).

To start the board game, the teacher or the educational professional will read a small introductory text in the manual that summarizes the game and its purpose.

The game has 100 questions constructed based on the interviews of students of two Brazilian high schools, books information and specialized sites in the subject about venomous and poisonous animals. These questions are distributed among the environments: House $(\mathrm{n}=12)$, City $(\mathrm{n}=12)$, Forest $(\mathrm{n}=12)$, Field $(\mathrm{n}=$ 16), Sea $(n=16)$ and Health Station $(n=32)$ environments. The questions were not divided with the same number of questions for each environment since we have a number of different houses for environments. The cards of different environments are represented by different colors to each environment (House: red, City: gray, Forest: green, Field: orange, Sea: blue and Health Station: white), preventing confusion on reading them (Figure 1).

All the environments, excepting the Health Station, has three types of different houses: 1) Informative house, where the participant will answer the questions or read a curiosity, 2) Luck or Bad luck Houses that can result in acceleration or delay in the game and 3) Animal House, which means that the player was envenomed by a venomous/poisonous animal and at this moment the player will be directed to the Health Station. The player may leave if answer correctly to a question. A mediator must previously be selected to read the cards, and the preference is for the teacher that may explain better the rules. 

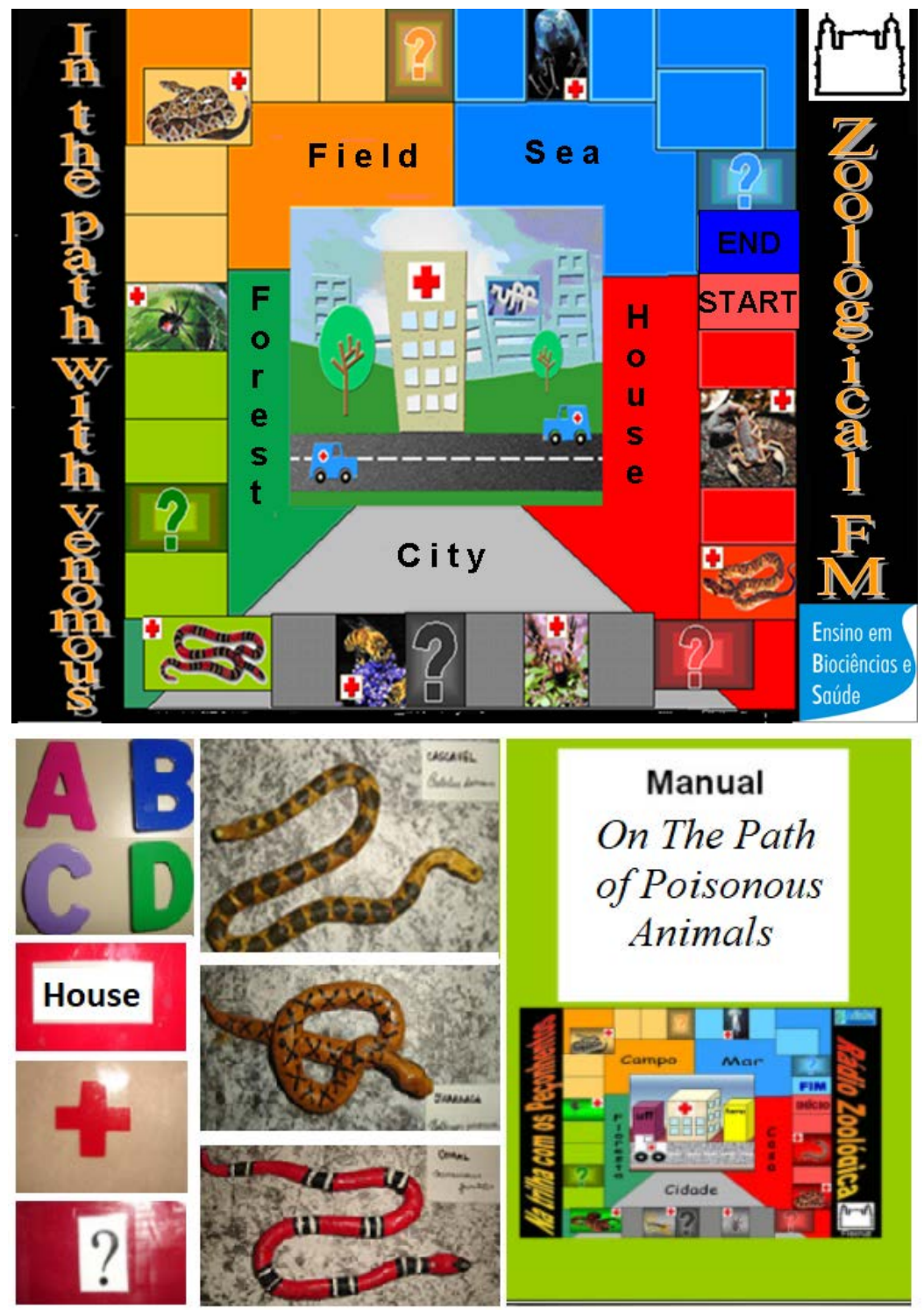

Figure 1. Board game "On the Path of Poisonous Animals". The cardboard (up), colored letter of the groups/teams (A, B, C and D), special cards that accelerate or delay the group, snakes models (biscuit) and manual of the game (down).

The mediator will begin the game reading to the class the invitation below:

"Attention students of the College!!!! The Zoological Radio FM is with a great promotion with the board game 'In the Path with the venomous' that is very easy to participate. Let's divide you into groups and walk through different environments in this insane board game, which includes a House, a City, a Forest, a Field, a Sea and a Health station. In this pathway you will find venomous and poisonous animals. Pay attention to the questions through the pathway and remember that venomous animals are those that possess a gland of poison and an anatomical structure to inoculate it into the prey. It can be teeth, stings, thorns and etc. In contrast, the poisonous animals are animals that produce poison, but do not have these inoculator's apparatus. These animals provoke poisoning 
through the contact, compression or ingestion. The team that arrives first at Zoological Radio will have to answer the final question to be the greatest winner of all. The winner will be LIVE with us during this month and will participate in the talkshow 'Do you have fear of poison?'. Participate and do not lose this chance! Only here on Zoological Radio FM."

All cards have the answer on the back, and each team should answer the question within approximately 2 minutes monitored with a clock or cell phone.

A manual of the game was produced to inform about rules and steps that basically consist of:

1) Dividing the class into two, three or four teams or groups. The game was idealized to be played by, at least two (2) or in the maximum (4) teams, but it does not have a limited number for the participants of the teams. The board can be used in a carpet format, so instead of the letter, the students can walk on the board.

2) Choosing the first team that will start the game and obligatorily will initiate in the environment House.

3) Answering the question of the Zoological Radio FM. If the answer is wrong, this gives a chance to another team to earn points in the game if their answer is right, and thus successively until having a winner.

4) Fulfilling the game with the pieces and points to the team in case of the right answer (100 points). In case of a wrong answer, the groups don't receive points and stay at the same place.

\section{Results and Discussion}

The educative games provide reflection, exchange of experiences, questions in a playful environment, helping students to establish knowledge, developing and individual opinions. Our game was initiated by an invitation, as proposed by Macedo, 1995 with a playful-pedagogical strategy presented in a dynamic way about different topics (e.g. difference between venomous and poisonous animals, examples of these animals, places where they can be found and prevention against accidents).

In the sequence of the game, the previous concepts analysis of the high school students revealed that many of them did not remember about the topic and few had answered correctly. These students did not know the difference between venomous and poisonous animals and most were afraid of venomous animals for reasons mainly related to health, which reinforced the need of pedagogical material on the topic (not shown). They also think that it is important to have a better knowledge about the subject, also allowing us to know the main doubts and errors, helping on planning the game, also being added information to fulfill the absent information of didactic books.

During the test, the students answered the game's questions and accumulated points. They received 100 points for each correct question and in the case of wrong answer, neither the team did not move forward nor received any point. 
The team that arrived first at Zoological Radio FM had to answer a final question, being able to choose from which environment the question was. The winner is the group that answered the question correctly, or the team will be declassified, giving the chance to the next/nearest team to answer a new question, until we have a winner.

The board game was presented to a $3^{\text {rd }}$-year-high-school class on a state public school, to two different classes with 26 students each one. In this evaluation, we tried to identify dynamic problems in the game using a pre and post-evaluation strategy. According to our analysis, most students (73\%) did not know the difference between venomous and poisonous animals before the game. This number is reduced to $10 \%$ after the game interaction, showing the understandability of the game by these students (Figure 2).

Before applying the game, students were asked which animals they considered venomous. Figure 3 shows the shift in the profile of animals cited by these groups after the test with the game.
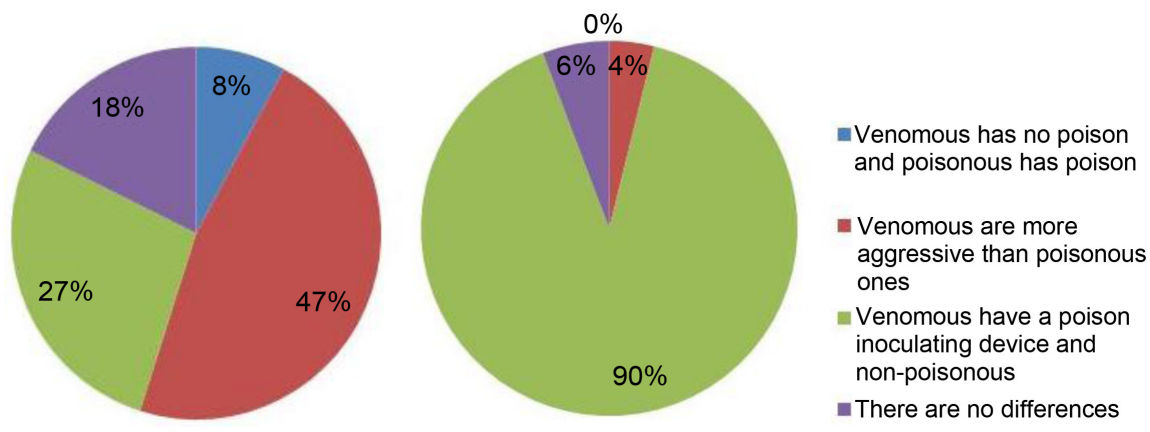

Figure 2. Comparison of the concepts of $3^{\text {rd }}$-year-high school students previously (left) and after (right) using our board game "On the Path of Poisonous Animals". Question: What is the difference between venomous and poisonous animals?

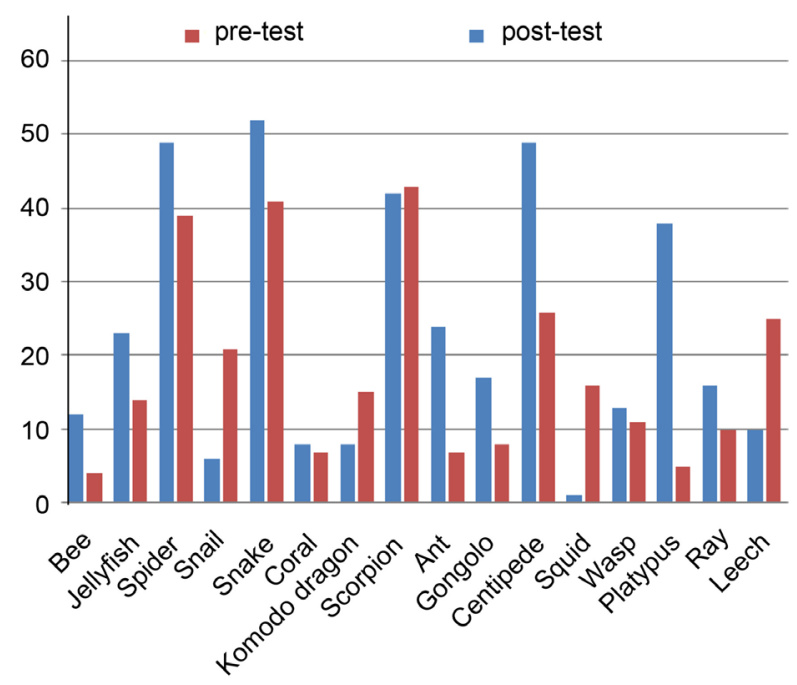

Figure 3. Comparison of venomous/poisonous animals cited by the $3^{\text {rd }}$-year high school students $(n=52)$ previously and after the test. In red the data before they played the game (pre-test) and in blue the data after the game (post-test). 
These results show that our educational game allowed the understanding of the concept about venomous animals and the differences between the poisonous ones. These data also suggested that the use of this dynamic game increased their knowledge, and can be applied to explore several topics about these animals. This is an open game and the teacher may create new questions about anything related to them.

During assessing the students' opinion about the game, we observed almost unanimous opinion of both classes that the game was cool, fun, educational and also helps in the prevention and treatment of accidents with venomous animals (Figure 4).

We also offered a space for the students write about the game (see below). Interestingly, their opinions showed the potentiality of the game exploring by teachers in the future with other themes.

"Great! I learned many things that I didn't know." (Student 3 )

"Very important to know how to treat venomous animal bites." (Student 24)

"Interestingly, through it we learned several things about venomous and poisonous animals." (Student 6)

\section{Final Remarks}

This game was produced on the basis of previous concepts of high school students, looking for overcome deficiencies and difficulties found related to the complex thematic of animals that use venom as a biological weapon on their environment.

Is was possible to observe during testing our game that the use of educational tools with different dynamics may enhance interactivity among students, also promoting discussion among them. The game was able to shift their understanding of previous concepts, and able to stimulate the dialogue which was one the main objective of this work, including to acquire the knowledge about venomous animals, how to proceed in accidents as well as their prevention. In
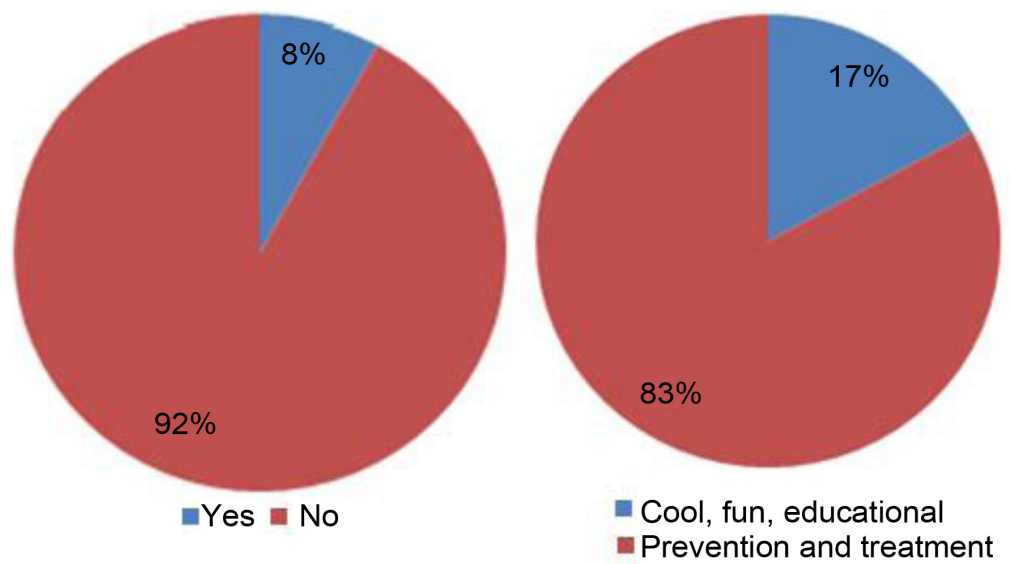

Figure 4. Answer of $3^{\text {rd }}$-year-high school students from two schools in the state of Rio de Janeiro to the questions: "Did the game address issues that you did not know?" (left) e "What do you think about the game?" (right) 
addition, the perception of the ecological importance of each animal has increase.

These data also reinforced that educational materials and science experiences should be more use, as the education enhanced when different strategies are used together. These different tools (games, models, lab experiments and interactive classrooms) are capable of promoting a greater dialogue among different knowledge areas, expanding the capacity for discussion among students involving different themes. Our game may be applied in more opportunities in different segments and disciplines as allow from writing texts about them, to discuss environment where they live, number of population, biotechnology perspective os biodiversity, among other different perspectives.

\section{Acknowledgements}

We thank CAPES, CNPq and Faperj for the fellowships and financial support.

\section{Conflicts of Interest}

The authors declare no conflicts of interest regarding the publication of this paper.

\section{References}

Amaral, C. F. S. et al. (2001). Manual of Diagnosis and Treatment of Accidents by Venomous Animals (120 p.). Brasília: Health Communication and Education Advisory/Ascom/Pre/FUNASA.

Azeredo, T. V., Fragel-Madeira, L., De Souza, C. M. V., Pereira, G. R., Coutinho-Silva, R., \& Alves, G. H. V. S. (2020). Artrópodes e a divulgação científica: Uma oportunidade para o diálogo em saúde. Ensino, Saúde e Ambiente, 13. https://doi.org/10.22409/resa2020.v13i1.a39905

Brazil (2020a). National Curriculum Parameters for High School. Natural Sciences, Mathematics and Its Technologies. Brasília: MEC, Ministry of Education. Secretariat of Medium and Technological Education.

Brazil (2020b). Manual for Diagnosis and Treatment of Accidents by Venomous Animals (112 p.). Brasília: MS. Ministry of Health. National Health Foundation (Funasa). http://www.funasa.gov.br

Bryan, J. (2009). From Snake Venom to ACE Inhibitor: The Discovery and Rise of Captopril. The Pharmaceutical Journal, 282, 455-456.

Cardoso, F. S., Dumpel, R., da Silva, L. B. G., Rodrigues, C. R., Santos, D. O., Cabral, L. M., \& Castro, H. C. (2008). Just Working with the Cellular Machine: A High School Game for Teaching Molecular Biology. Biochemistry and Molecular Biology Education, 36, 120-124. https://doi.org/10.1002/bmb.20164

Dossenbach, H. D. (1999). Beware We Are Poisonous! How Animals Defend Themselves (40 p.). Woodbridge: Blackbirch Press.

Jacobs, R., \& Baum, M. (1987). Simulation and Games in Training and Development. Simulation and Games, 18, 385-394. https://doi.org/10.1177/104687818701800305

Macedo, L. (1995). Games and Their Importance at School. Caderno de Pesquisa, 93, 5-10. 
Malone, T. W., \& Lepper, M. R. (1987). Making Learning Fun: Ataxonomy of Intrinsic Motivations for Learning (Vol. 3, pp. 223-253). Hillsdale, MI: Lawrence Erlbaum.

Pierozan, C., \& Brancher, J. D. (2004). The Importance of the Educational Game and Its Advantages in the Teaching and Learning Process. National Congress of Hypermedia Learning Environments (Conahpa). 